\title{
Dimensão relacional da atividade de cuidado e condiçôes de trabalho de auxiliares de enfermagem em uma unidade neonatal
}

I ${ }^{1}$ Letícia Pessoa Masson, ${ }^{2}$ Jussara Brito, ${ }^{3}$ Milton Athayde I

Resumo: Este artigo analisa as condiçôes de trabalho de auxiliares de enfermagem que atuam em Unidade Neonatal, considerando a dimensão relacional da atividade de cuidado. Tendo como principais referências epistemológicas a concepção canguilhemiana de saúde e a perspectiva ergológica, a pesquisa se pautou em abordagens clínicas do trabalhar, incluindo métodos diretos (observaçôes), indiretos (conversas e encontros sobre o trabalho com as auxiliares) e análise de documentos relativos às normas antecedentes desse trabalho. Analisouse fundamentalmente a produção linguageira dos coletivos. Entre os resultados encontrados, destacam-se: o desenvolvimento dessa atividade de cuidado implica intensa mobilização das trabalhadoras; a possibilidade de não atender às mães que chegam para ter seus bebês parece ser mais nocivo à saúde dessas profissionais do que trabalhar com um número excessivo de pacientes. Concluiu-se que as condições precárias de trabalho são potencialmente produtoras de sofrimento patogênico, uma vez que a realização prazerosa e bem-sucedida dessa atividade é dificultada.

> Palavras-chave: Unidade Neonatal; auxiliares de enfermagem; condições de trabalho, atividade de cuidado; maternidade.

\author{
1 Mestre em Saúde Pública pela \\ ENSP/FIOCRUZ e doutoranda \\ em Psicologia Social pela \\ UERJ. Endereço eletrônico: \\ leticiapessoa@yahoo.com.br \\ 2 Pesquisadora da Escola \\ Nacional de Saúde Pública \\ Sergio Arouca (ENSP/FIOCRUZ) \\ Doutora em Saúde Pública, com \\ Pós-doutorado em Ergologia. \\ Endereço eletrônico: jussara@ \\ ensp.fiocruz.br \\ ${ }^{3}$ Professor do Instituto de \\ Psicologia da Universidade \\ do Estado do Rio de Janeiro \\ (UERJ). Doutor em Engenharia \\ de Produção/Ergonomia, com \\ pós-doutorado em Ergologia. \\ Endereço eletrônico: athayde. \\ milton@gmail.com
}

Recebido em: 13/05/2009 Aprovado em: 22/06/2010 
Os trabalhadores de enfermagem de nível fundamental e médio correspondem à maciça maioria dos funcionários dos hospitais, são majoritariamente mulheres ${ }^{1}$ e estão na linha de frente do processo terapêutico, situando-se no trabalho de cuidado direto dos pacientes. Essas profissionais realizam atividades tidas como manuais e mais simples, se comparadas às exercidas pelos enfermeiros e médicos que prescrevem e organizam formalmente seu processo de trabalho -, tendo uma possibilidade muito restrita de intervir sobre ele (LOPES; LEAL, 2005; GAÍVA, 2004; OSÓRIO DA SILVA C, 2002; SCOCHI et al., 1997; REGO, 1993).

Nesse sentido, Osório-da-Silva (1994) afirma que a divisão do trabalho hospitalar tem consequências não apenas sobre a qualificação dos trabalhadores, mas também sobre os sentimentos de maior ou menor valorização do trabalho realizado. Estudos sobre o pessoal de enfermagem, especialmente o de nível fundamental e médio, apontam que essas profissionais sentem-se pouco reconhecidas e valorizadas no seu trabalho, apresentando, muitas vezes, sofrimento psíquico patogênico relacionado a esses fatores (REGO, 1993; OSÓRIO DA SILVA, 1994; MOREIRA, 1999; ESTRYN-BEHAR M et al., 2002).

Segundo Seifert \& Messing (2004), os cuidados de enfermagem são, antes de tudo, de natureza relacional e, nesse sentido, exigem tempo e certa continuidade presencial das profissionais junto aos pacientes e seus familiares. As autoras salientam que, ao encontrar condições inadequadas de trabalho para desenvolver a "natureza relacional" (p.2) na regulação de suas atividades, as profissionais acabam por privilegiar a realização das tarefas prescritas, reduzindo sua dedicação aos aspectos relacionais do trabalho. No entanto, a relação com os pacientes seria fonte de prazer para essas trabalhadoras e, quando tal relação é dificultada pelas condições de trabalho, acaba acarretando a perda de parte do seu sentido, podendo gerar impactos no seu nível de fadiga e de frustração e mesmo uma diminuição de sua disponibilidade aos pacientes. Nesse sentido, Seifert \& Messing chamam a atenção para o fato de que a qualidade dos cuidados oferecidos está intimamente ligada à qualidade do emprego, ou seja, do contrato e das condições de trabalho oferecidas às trabalhadoras.

Especificamente com relação às auxiliares de enfermagem que atuam em Unidades de Tratamento Intensivo Neonatais (UTIN), pode-se dizer que elas são as profissionais que mais convivem com os bebês internados, 
sendo responsáveis pelos chamados "cuidados de rotina", tais como higiene, administração de medicação, alimentação e verificação dos sinais vitais, entre diversas outras tarefas (LAMY FILHO, 2003). São responsáveis também pela arrumação das incubadoras e dos berços, e devem fazer o registro de tudo o que observam sobre o bebê durante a realização de seus cuidados. Além disso, são chamadas para acompanhar a realização de diferentes procedimentos pelos demais integrantes da equipe de saúde junto aos bebês. Compõem, ainda, o grupo profissional de maior contingente na Unidade (SCOCHI, 1997; SEIFERT; MESSING, 2004), sendo as que estão em maior contato também com os familiares dos bebês, com os quais estabelecem uma relação não apenas de oferta de cuidados, mas, mais propriamente, de uma coprodução de serviço (ZARIFIAN, 2001). Nesse sentido, tratar a questão da invisibilidade (ou melhor, da invisibilização) da dimensão relacional da atividade dessas profissionais e de sua saúde nos parece algo incontornável para se pensar o trabalho e a produção de serviços no setor saúde.

Neste artigo ${ }^{2}$ focalizaremos a temática das condições de trabalho de auxiliares de enfermagem de uma Unidade Neonatal (UN), discutindo-a a partir de uma investigação desenvolvida em um hospital-maternidade público do município do Rio de Janeiro, entre maio de 2006 e janeiro de 2008. O estudo se deu na perspectiva de compreender-transformar a relação entre a (invisibilidade da) atividade altamente relacional dessas trabalhadoras e sua saúde, levando-se em conta as exigências de produtividade e qualidade presentes nesse tipo de trabalho.

Entendemos que essa invisibilização é gerada principalmente em decorrência da histórica divisão sexual e social do trabalho presente em nossa sociedade. Engendra-se nesse contexto uma subvalorização e mesmo uma valoração negativa de um coletivo profissional quase inteiramente feminino, em princípio pouco escolarizado/qualificado formalmente. Não obstante, verificamos não apenas sua competência no desenvolvimento das atividades de trabalho, como também uma qualificação para além da requisitada para o cargo em questão.

Quanto à dimensão relacional da atividade de trabalho, esta envolve diversos aspectos imbricados e dificilmente isoláveis, tais como a produção linguageira (FAÏTA, 2005) e a dimensão cognitiva e afetivo-emocional, ou seja, o envolvimento, no desenvolvimento da atividade, de todo o corpo (o corpo-si, conforme SCHWARTZ, 2007) de quem trabalha. 
Com esta pesquisa, buscamos contribuir para dar visibilidade aos aspectos ocult(ad)os dessa atividade, acreditando que tal visibilização pode trazer benefícios à saúde dessas trabalhadoras, já que nossa perspectiva é a de que compreender o trabalho é uma poderosa ferramenta para transformá-lo (assim como as tentativas de mudança também podem colaborar para melhorar o entendimento do que ocorre nessas situações).

\section{Referenciais teórico-metodológicos}

Tivemos como principal orientação a concepção canguilhemiana de vida-saúde (CANGUILHEM, 2002) e a perspectiva ergológica, tendo então a atividade de trabalho (considerada de modo amplo, e não apenas em seu enquadre prescrito) o ponto de vista privilegiado da análise (SCHWARTZ; DURRIVE, 2007). A pesquisa se pautou teórico-metodologicamente em abordagens clínicas do trabalhar, como a ergonomia da atividade (GUÉRIN et al., 2001), o Modelo Operário Italiano de Luta pela Saúde (ODONNE et al., 1981), a psicodinâmica do trabalho (DEJOURS, 2004) e a clínica da atividade (CLOT, 2006), incorporando também as proposições e os estudos empíricos sobre a lógica competência e o paradigma da relação de serviço (ZARIFIAN, 2001b).

Assim, a saúde é considerada como capacidade normativa (CANGUILHEM, 2002) e possibilidade de recriação do meio em que se vive e trabalha, na busca de sua renormatização e recentramento, em função de valores próprios (individuais e coletivos) e dentro de uma situação de trabalho concreta. Nessa concepção, em vez de se definir por simples oposição à doença (configurada, no caso da saúde mental, em quadros psicopatológicos), "saúde" significaria a conquista de condições favoráveis ao desenvolvimento da capacidade de lidar com o sofrimento (dando a ele um rumo criativo, não patogênico) e o eventual adoecimento (DEJOURS, 1986).

Em relação à perspectiva ergológica, explorando a linhagem canguilhemiana, esta se baseia no princípio de que a sinergia do trabalho em conjunto de profissionais da ciência e dos protagonistas da atividade em foco é condição para compreender $\leftrightarrow$ transformar o trabalho. Para a construção de uma zona comum, de uma "comunidade" entre trabalhadores e cientistas, Schwartz (2000) propõe um "dispositivo dinâmico de três polos". O autor entende que esse dispositivo é consequência direta da ideia de renormatização, isto é, o 
pressuposto de que a atividade de trabalho se transforma permanentemente pela atuação dos seus protagonistas. Frente às variabilidades, ao acaso e aos equívocos da prescrição, ao verem sentido no que fazem, eles efetuam regulaçôes, ajustes, desvios, em relação com as normas antecedentes (geradas a priori, aí incluídas as prescrições), visando atingir os objetivos almejados, com menos desgaste físico e mental. Trata-se de um pressuposto que está articulado com as noções ergonômicas de trabalho prescrito e trabalho real (GUÉRIN et al., 2001; BRITO, 2009), bem como ao entendimento de que, para dar conta das exigências do trabalho, os trabalhadores fazem uso de si (SCHWARTZ, 2000), não apenas segundo as determinações exteriores ("uso de si pelo outros"), mas também seguindo suas próprias lógicas ("uso de si por si”).

A percepção dessa complexidade, da realidade sempre mutante das atividades, provoca um "desconforto intelectual" nos que estudam o trabalho, deles exigindo humildade epistêmica. Considerando a riqueza do trabalho enquanto experiência, os saberes disciplinares precisam também ser testados e validados no decorrer da relação dialógica que se estabelece ao operar com o citado dispositivo dinâmico de 3 polos (DD3P). Ressalta-se, ainda, que os saberes produzidos/ investidos pelos trabalhadores nas situações concretas de trabalho - mobilizando uma inteligência da prática, conforme Dejours (2004) - necessitam de diferentes formas de julgamento/avaliação, gerando o que o autor denomina por sabedoria da prática. Porém, esses saberes também demandam descobertas e sistematizações mais estáveis, presentes nos estudos científicos sobre o trabalho. Assim, como afirma Schwartz (2000), cada um tem sua zona de cultura e incultura.

Nesse dispositivo de três polos proposto por Schwartz, o primeiro comporta materiais teórico-conceituais e conhecimentos gerados por diversas disciplinas a respeito do trabalho. $\mathrm{O}$ segundo diz respeito justamente aos saberes e valores gerados pela experiência dos trabalhadores em sua atividade, desenhando-se aí um campo em que atua uma dinâmica de "forças de convocação e validação". Os protagonistas da atividade em foco convocam os atores e materiais do primeiro polo para auxiliá-los no compreender $\leftrightarrow$ transformar suas situações de trabalho e reconvocam posteriormente esses mesmos atores e materiais, colocando-os em confronto com seus saberes e experiência, em um processo de validação. Schwartz (2000) ressalta a necessidade de um trabalho conjunto entre protagonistas da atividade em foco e pesquisadores profissionais, assinalando as dificuldades 
encontradas nessa construção - muitas delas relacionadas à dificuldade de traduzir a experiência da prática do trabalho em palavras.

$\mathrm{O}$ terceiro polo do dispositivo é pensado como condição de sinergia e fecundidade do encontro entre os saberes. Esse é o polo das exigências éticas e epistemológicas, que se baseia na ideia do outro - do parceiro no processo - como alguém que vai ensinar algo sobre o que faz, sem a pressuposição de já se saber, de antemão sobre o que ele faz, por que faz, nem quais são seus valores e como eles têm sido "(re)processados". Assim, o terceiro polo impõe, de um lado, certa humildade dos profissionais da ciência para retornar à atividade, foco da análise; e, de outro lado, uma aceitação da disciplina do conceito e de sua aprendizagem por parte dos protagonistas das atividades em análise (SCHWARTZ, 2000). Enfim, entre os três polos, deve-se considerar que há uma relação dialética, não hierarquizada.

Assim, a possibilidade de abordar o trabalho a partir de um encontro fecundo entre saberes da experiência (do coletivo de auxiliares de enfermagem) e conhecimentos estabilizados/disciplinares (baseados na pesquisa científica) foi experimentada ao longo da investigação a que nos referimos, gerando a construção e a validação de hipóteses sobre a relação entre condições de trabalho, a dimensão relacional da atividade e a saúde de auxiliares de enfermagem em uma UN.

\section{A Unidade estudada}

Trata-se da Unidade Neonatal $^{3}$ de um hospital público municipal, especializado no atendimento à saúde da mulher, localizado em um bairro central do município do Rio de Janeiro. Conta com quatro setores: a Unidade de Tratamento Intensivo (UTIN), a Unidade Intermediária (UI) e a Unidade de Baixo Risco (UBR), também chamada Berçário de Baixo Risco (BBR) ou Unidade Mãe-Bebê, além da Unidade Canguru (alojamento conjunto especial para a realização de uma das etapas do chamado "Método Canguru"). Além disso, o serviço de Neonatologia conta com os setores de medicação e material, nos quais os profissionais de enfermagem (auxiliares e enfermeiros) são escalados para trabalhar. A UTI apresenta vinte leitos para os neonatos; a UI, vinte e quatro leitos; a UBR oferece dez vagas; e a Unidade Canguru possui seis leitos para o chamado "binômio mãe-bebê".

O serviço de Neonatologia conta diariamente com os seguintes profissionais: cerca de quatro médicos pediatras plantonistas, que se dividem por todo o hospital (sala de parto e alojamento conjunto - para bebês que nascem sadios 
e mães -, além da Unidade Neonatal), quatro enfermeiros plantonistas de dia e

três enfermeiros plantonistas à noite, além de fonoaudiólogos, fisioterapeutas e psicólogos, entre outros profissionais de rotina, que atuam em todo o Hospital durante os dias úteis. A Unidade conta ainda com uma média de 18 auxiliares de enfermagem plantonistas em cada turno de trabalho de 12 horas. $\mathrm{O}$ regime de plantão no hospital é de 12 horas trabalhadas por 60 horas de descanso.

\section{As auxiliares de enfermagem da Unidade Neonatal estudada}

O coletivo de auxiliares é formado por seis coletivos de plantonistas: três diurnos e três noturnos. Há cerca de 100 trabalhadoras nesse cargo, embora a grande maioria tenha concluído o curso técnico de enfermagem, não havendo, no entanto, diferenciações nas atividades desempenhadas pelo conjunto.

A quase totalidade (99 das 100) dessas profissionais é composta por mulheres. $90 \%$ são servidoras públicas municipais, sendo que 10\% destas realizam a dupla jornada (DJ) - modalidade de plantão extra, realizado regularmente dentro do próprio setor do hospital onde já trabalham, o que só é possível para as profissionais concursadas. Quanto às outras auxiliares, (10\%) estas estão vinculadas à Prefeitura do Rio de Janeiro por meio de "contrato temporário", vínculo que entendemos como um dos aspectos gritantes da precarização das condições de trabalho no setor.

Em janeiro de 2006, o setor de Neonatologia funcionava com um déficit de 37 auxiliares de enfermagem (cerca de seis profissionais por plantão), considerando as próprias recomendações da Secretaria Municipal de Saúde (SMS) da Prefeitura do Rio de Janeiro sobre o dimensionamento de profissionais para a assistência de neonatos (Resolução SMS 864 de 12 de abril de 2002). É importante ressaltar que a realidade traçada nos parágrafos anteriores refere-se ao que encontramos no hospital entre o início do ano de 2006 e o final de 2007, quando da realização da pesquisa em foco neste artigo.

O método de pesquisa incluiu:

- Visitas à Unidade Neonatal, envolvendo observações e conversas com as trabalhadoras (com exceção da Unidade Canguru);

- Levantamento e análise de documentos relativos às normas antecedentes e à prescrição do trabalho (rotinas escritas do trabalho na UN, legislação do exercício profissional de enfermagem, um relatório da chefia sobre a necessidade 
de maior provisão de pessoal, a escala de serviço do mês em que se iniciou a pesquisa e a planta física da unidade);

- Encontros sobre o trabalho envolvendo uma Comunidade Ampliada de Pesquisa (BRITO; ATHAYDE; NEVES, 2003; BRITO; ATHAYDE, 2003), nos quais circulou uma comunidade dialógica (FRANÇA, 2007), composta por auxiliares de enfermagem e pesquisadoras, para discussão e análise da atividade em relação à saúde.

Para uma aproximação inicial com as auxiliares de enfermagem e com a atividade de trabalho dessas profissionais, além da aproximação com o próprio funcionamento cotidiano da Unidade, foram feitas visitas (estratégia de inspiração etnológica) à UN nos diferentes plantôes (inclusive os noturnos), buscando observar e registrar as diferentes situações e coletivos que ali atuavam. Após uma análise inicial das normas antecedentes ao trabalho e dos materiais surgidos durante as visitas (todas registradas em relatórios), foram planejados os encontros sobre o trabalho (todos registrados em gravador, gerando relatórios), nos quais procuramos discutir sistematicamente com as trabalhadoras, a partir de temas geradores (na terminologia freireana) pertinentes à sua atividade, procurando desenvolver o diálogo sinérgico entre saberes científicos e saberes da prática.

Quanto aos encontros sobre o trabalho, para Durrive (2001), seu "animador" deve procurar favorecer a dinâmica gerada pelo terceiro polo do dispositivo (éticoepistêmico). Assim, após ressaltar a importância do ponto de vista da atividade e chamar a atenção para a sua complexidade, para os desafios e mobilizações aí implicados, bem como para a dificuldade que se tem em enquadrar tal atividade conceitualmente, o animador deve buscar convencer os participantes de que há necessidade de uma rigorosa verbalização daquilo que a atividade ensina. Ele deve enquadrar o debate através do "método da dialética de registros", que consiste em levar os participantes a distinguir com clareza o que, na sua atividade, faz parte do registro do formalizado e o que provém do segundo registro (o das renormatizaçôes), pois essa é a sua verdadeira natureza: a gestão do hiato entre os dois registros, para que, apesar de tudo, o trabalho seja realizado.

Nessa perspectiva, foram realizados seis encontros de cerca de uma hora, dentro da jornada de trabalho, no Hospital, com a participação de nove auxiliares ${ }^{4}$ de um dos plantões, que se revezavam entre as reuniões, gerando grupos de três a cinco participantes. 
Os encontros se dividiram em: pré-encontro (apresentação e discussão dos temas geradores dos encontros seguintes); encontro I ("Formação profissional"); encontro II ("Coletivos de trabalho"); encontro III ("Organização do trabalho"); encontro IV ("Condições de trabalho") e encontro de fechamento. Em cada um deles houve a apresentação de conceitos e análises pertinentes a cada tema, seguidas da sua discussão, colocando em foco a atividade de trabalho na UN em relação com a saúde das trabalhadoras. Para auxiliar a animação dos debates, expusemos falas das próprias auxiliares, ditas durante as visitas à $\mathrm{UN}$, facilitando a confrontação das participantes a elementos do seu cotidiano de trabalho e também ao saber provindo de sua própria experiência.

Durante a análise, buscamos compreender a presença da dimensão relacional e as possibilidades das auxiliares de enfermagem agirem sobre seu meio. A análise efetuada se deu fundamentalmente sobre a produção linguageira emergente nos encontros, destacando a movimentação dos diálogos (a motricidade dialógica).

Em seguida, houve um retorno ao hospital visando desenvolver um processo de validação das análises iniciais junto às auxiliares de enfermagem. Esse retorno se deu através de quatro novos encontros sobre o trabalho, ${ }^{5}$ para os quais foram preparadas exposições e elaboradas sínteses dos resultados e análises. Essas sínteses foram organizadas em forma de cadernos especificamente elaborados para esse fim, apresentando conteúdo referente aos resultados do estudo, além de espaços para as auxiliares realizarem anotações ao longo de nossas apresentações, possibilitando a discussão dos resultados.

Os temas abordados nesse processo de validação foram os seguintes: "A formação profissional das auxiliares de enfermagem", "As condições de trabalho das auxiliares de enfermagem" e "A organização do trabalho e a formação de coletivo de trabalho na atividade das auxiliares de enfermagem". Houve ainda um encontro informal, no qual se discutiu de forma livre.

Neste texto, discutiremos os resultados concernentes às condiçóes de trabalho, a partir dos materiais gerados especialmente no Encontro IV (sobre as condições de trabalho) e no momento de validação desses achados durante o retorno ao hospital.

Em relação aos aspectos éticos, a pesquisa seguiu todas as exigências, tendo o projeto sido aprovado tanto pelo Comitê de Ética em Pesquisa da ENSP (parecer n⿳o 28/2006 do Comitê de Ética em Pesquisa da ENSP - CAAE: 00029.0.031.00006), quanto pelo do hospital onde o trabalho de campo foi realizado. 


\section{Resultados e discussão}

De acordo com o propósito deste artigo, os resultados aqui discutidos referemse exclusivamente ao tema gerador denominado "condições de trabalho", em interface com a dimensão relacional da atividade em foco. Concebem-se como condiçôes de trabalho os meios disponibilizados (físicos, químicos, materiais, espaciais, de definição de objetivos e procedimentos a realizar, meios técnicos colocados à disposição, condições salariais, qualificação, etc.) para a realização de uma atividade de trabalho. Como já dito, nossa análise se deu fundamentalmente sobre a produção linguageira dos grupos, privilegiando a motricidade dialógica. Esse tipo de análise permitiu a emergência de algumas questôes, que se definem pela imbricação das condições materiais de trabalho com as imateriais (relacionais), como as que destacaremos, a seguir, ao longo da apresentação da análise dos resultados.

\section{A superlotação do setor e o patrimônio de valores do coletivo}

Ao discutirmos a relação entre a superlotação de pacientes/usuários, bastante comum no setor, a qualidade do cuidado oferecido e as consequências para a saúde das auxiliares de enfermagem, as participantes afirmaram um paradoxo: revelase gratificante poder atender a pessoas que já passaram por diversos hospitais sem receber socorro, mesmo quando assumir essa responsabilidade pode contribuir para gerar a superlotação do setor.

O confronto das participantes com a frase "a política do Hospital é a de ser um "coração de mãe", não tem limite de entrada no hospital", dita por uma enfermeira durante uma visita, parece ter contribuído para que as auxiliares expressassem uma dimensão corporal-afetiva ("do coração") do ofício da enfermagem e a forte relação entre o trabalho de "acolhimento" feito naquele hospital e a sua própria saúde. Ou seja, haveria maternidades sem "coração de mãe", nas quais os ofícios pertinentes a esse tipo de serviço seriam discutíveis. Nesse sentido, entendemos que essa regra de que um lugar que é "para mãe" tenha "coração de mãe", como elas próprias definem, possa representar uma regra de ouro dos ofícios (CRU, 1987) que fazem funcionar uma maternidade referência.

De acordo com a produção linguageira das auxiliares, pudemos notar algumas regras de ofício implícitas presentes não apenas em seu coletivo profissional, mas possivelmente ligadas ao patrimônio de valores daquele hospital: 
- Pode não se ter todas as condições para o atendimento dos clientes ("mesmo a gente sabendo que falta muita coisa, mas a gente ainda sabe que se a gente atender, a gente não vai trazer tantos prejuízos pra essa pessoa");

- Pode ser que a superlotação gere problemas na assistência (infecção hospitalar, menor atenção no cuidado dos bebês e seus familiares) ou uma sobrecarga de trabalho prejudicial à saúde dos profissionais ("nós que estamos trabalhando, às vezes a gente se queixa, né”; “a saúde de quem cuida também é fragilizada e (...) essa situação fica mais difícil pra gente, porque não [vamos deixar de atendê-los, mesmo que] precariamente".)

- Mas, o que não se pode (tendo em vista não apenas a saúde dos clientes, mas a das próprias auxiliares), é deixar de atendê-los ("quando você se coloca no lugar da pessoa que tá lá fora querendo uma vaga... aí você tem que [atender]...”; "é muito gratificante, né"), pois isso significaria deixar de "ter coração".

Assim, podemos perceber que, por mais que o "acolhimento" de um número maior de pacientes, associado a problemas crônicos de déficit de pessoal, possa representar algo ruim para o trabalho das auxiliares, isto também é bom, no sentido de que mostra a construção de um patrimônio de normas e valores próprios àquele espaço de trabalho. Essa construção tem a ver com uma incorporação do hospital pelas auxiliares como algo que é delas próprias - é do corpo de ofício. Esse movimento de construção institucional (maternidade) as torna membros de uma organização (aquela maternidade específica) que apresenta um trabalho de destaque, reconhecido (nesse sentido, uma referência) nem que seja por possuir o fundamental - um "coração aberto" - frente à incapacidade da rede pública de saúde em dar conta das demandas dos usuários desses serviços.

É importante ressaltar também o aparente paradoxo de que atender em condiçōes precarizadas (algumas vezes degradadas) não anula a tentativa das trabalhadoras de sempre fazer o melhor. Trata-se de algo caro a elas e que se expressa, por exemplo, ao realizarem ações visando impedir a alta de bebês que ainda não alcançaram autonomia na amamentação, assim como desincentivar a permanência no hospital de bebês que já estão com um bom prognóstico, estimulando as mães para a independência no cuidado. Essa questão (da alta hospitalar) envolve um complexo trabalho das auxiliares, seja com as mães, no sentido de fortalecer sua segurança com o filho, seja em um campo permeado de dificuldades como o do diálogo com os médicos (também pressionados pela 
disponibilização de novos leitos). Não obstante, mostra-se uma preocupação que faz parte do dia-a-dia das auxiliares e que não tem a visibilidade ou o reconhecimento que deveria.

Portanto, não atender as mães que ali chegam para ter seus bebês parece ser mais nocivo à saúde dessas profissionais do que o desgaste de trabalhar com um número excessivo de pacientes. "Se virar", "dar um jeito" para atender muita gente. Esta acaba sendo a rotina entre as auxiliares, uma vez que elas acham que ser preferível suportar essa sobrecarga de trabalho (e de riscos, como os trazidos pela superlotação da unidade) a negar o atendimento às mães e aos bebês, que ali chegam muitas vezes correndo risco de vida.

É nesse sentido que falamos de saúde enquanto modo de tornar o meio mais coerente com os próprios valores. Contudo, podemos interrogar em que medida tal mobilização buscando conciliar o inconciliável, prejudica a saúde? Como nos diz Clot (2006), "a interiorização psíquica dos conflitos de critérios associados a objetivos praticamente irrealizáveis conduz a novas dissociações”. Em que medida essa regra de ouro do ofício de quem trabalha em uma maternidade, que para ser de verdade precisa ter "coração de mãe", não estaria operando no quadro de um ofício em sofrimento, dado o quadro de precarização aí presente?

\section{Sobrecarga e mobilização do corpo-si}

A questão da invisibilização da sobrecarga de trabalho desencadeou um debate importante. Enquanto uma auxiliar falava que "mesmo que você tenha que pegar peso, em um CTI de adulto, você vai ter dez leitos, veja quantos leitos tem aqui!”, outra questionava:

eu acho que é meio complicado você comparar paciente adulto com paciente neonatal. O tempo que eu levo cuidando de um bebê é muito inferior ao tempo que eu vou levar só no banho de um adulto...

Uma terceira auxiliar chamou a atenção do cansaço físico decorrente no trabalho intenso na UTI neonatal, fazendo com que elas mal consigam sentarse durante os plantões. Lembrou-se também que, se os bebês são mais leves e menores do que adultos, por outro lado demandam maior observação (contínua) e ocupam menos espaço, possibilitando que a UTI neonatal contenha muito mais leitos do que uma de adulto, mesmo se a correlação de profissionais para cuidar deles seja semelhante. 
Em geral, os problemas de saúde foram motivos de poucas queixas das profissionais, mas, ao lhes indagarmos diretamente, ouvimos queixas relacionadas a movimentos repetitivos, como o de balançar o termômetro para medição rotineira da temperatura dos recém-nascidos, além de problemas de coluna e nos pés pelo fato de ficarem muito tempo de pé ("doente cuidando de outro doente, né, essa... é a nossa rotina").

Identificamos, assim, uma forte mobilização (invisibilizada) do corpo-si (SCHWARTZ, 2007) no trabalho na UN, explicitada ao falarem de "ficar em pé da hora que chega [até a hora de ir embora]...", das dificuldades em ter pausas durante o trabalho, e de que, mesmo estas, não significam um afastamento completo da atividade ("almoçar [no refeitório, no andar térreo] e, mesmo assim, com a cabeça aqui em cima”). Observa-se, então, um forte uso de si, completamente contrário a uma idéia de que o trabalho das auxiliares seria repetitivo e de pura execução. Trata-se na verdade de uma atividade complexa e fortemente incorporada, na qual o corpo-si está mobilizado, de forma permanente e completa.

Além disso, as trabalhadoras apontam que sua atividade exige uma grande polivalência (ou plasticidade), com a atribuição das mais diversas funções, para além da prescrição formal, envolvendo desde fazer "uma terapiazinha com as mães”, até observar que uma mãe precisa ser encaminhada ao Setor de Saúde Mental do hospital, por a notarem mais deprimida ou chorosa, por exemplo.

Sobre esse aspecto da sobrecarga de trabalho, podemos concluir que se trata de uma sobrecarga não apenas física, mas também cognitiva e fortemente afetiva. De acordo com uma auxiliar: "esse é um trabalho com uma grande sobrecarga emocional". Diante dessa afirmação, o coletivo presente no encontro comentou que essa questão é invisibilizada, até mesmo entre as próprias auxiliares, em decorrência da "rotina" (intensificada) de trabalho ("talvez nós mesmas nem percebemos que estamos trabalhando nesse ritmo esbaforido, né?!”). As participantes compararam tal invisibilidade com a adaptação e o costume que adquiriram em relação aos ruídos dos aparelhos da UTI.

\section{Ruídos e atenção contínua}

O barulho (...) eu to ficando surda, eu to ficando surda.

Em função dessa... superlotação, o quê que acontece? Os aparelhos não têm tempo pra descanso, coitados... 
Observamos diversas vezes, durante nossas visitas, auxiliares avisando as colegas sobre os apitos e alarmes das incubadoras, que tocavam com insistência. As incubadoras dos bebês de que as auxiliares estavam cuidando acabavam não sendo notados (de forma consciente) por elas, mas sim pelas colegas que estavam cuidando de bebês próximos. Segundo as participantes, um motivo que poderia estar contribuindo para fazer com que elas não percebessem ou demorassem para ouvir os ruídos, seria o fato de que esses alarmes, por estarem funcionando continuamente e não pararem para manutenção, apresentavam erros na deteç̧ão do estado dos bebês e disparavam muitas vezes desnecessariamente. Assim, as auxiliares pareciam escolher - mesmo que de maneira não consciente, mas muito corporal - confiar mais nos seus olhares que nas suas audiçôes ("o que eles [os alarmes dos aparelhos] fazem não condiz com o que você olha pra criança e você vê").

Poderíamos dizer que esta seria mais uma expressão da dimensão fortemente corporal da inteligência da prática (DEJOURS, 2004) presente na atividade dessas trabalhadoras, associada à precariedade das condiçōes materiais de trabalho a elas oferecidas. Mais uma vez as condições efetivas de trabalho remetem a um (re)trabalho de organização pelo coletivo (para além da organização prescrita do trabalho), outro componente da face oculta da atividade. Nesse caso, uma inteligência a favor da preservação da saúde e da realização de um trabalho de qualidade.

\section{As condições materiais e a dimensão relacional do trabalho}

A discussão sobre os problemas com os materiais utilizados no trabalho (escassez e/ ou má qualidade) e sua influência na realização do cuidado proporcionou um rico debate em nossa comunidade dialógica de pesquisa. Ao discorrer sobre a preocupação com a dor dos bebês, as auxiliares acabaram por falar de maneira muito intensa sobre o quanto tal sofrimento atinge a saúde delas próprias. Pareceunos, assim, que é quando falam das condições materiais e do sofrimento dos pacientes-usuários que elas conseguem melhor refletir e expressar o seu próprio sofrimento em relação ao ofício que exercem. Em nosso entendimento, mais do que ajudá-las a desenvolverem estratégias de ajustamento à adversidade (com base em uma abordagem do stress, conforme Lazarus e Folkman, 1984), é preciso mudar, ao menos em parte, esse cenário (especialmente tão nocivo aos usuários), 
sob pena de produção de quadros psicossomáticos e psicopatológicos. No caso do cuidado de bebês, de intervenção sobre seus corpos, a escassez ou a má qualidade dos materiais e instrumentos leva a atividades contrariadas ou mesmo amputadas (CLOT, 2006) das trabalhadoras - através da perda ou ausência persistente de condições concretas para o exercício do ofício e dos ideais institucionais até então existentes - conduzindo muitas vezes a sentimento de impotência, fadiga crônica, descompensações e ressentimento.

Nesse sentido, questionamos a ideia de que as condiçôes de trabalho geram apenas riscos, no sentido mais tradicional do termo, abrindo caminhos para se pensar que elas também geram riscos mais subjetivos, menos palpáveis e mais invisíveis à saúde dessas profissionais, os quais são geridos por elas ao longo de suas atividades.

$\mathrm{Na}$ perspectiva canguilhemiana que nos orienta, essa gestão dos riscos é feita inevitavelmente por qualquer vivente humano, mas devem-se garantir boas condiçōes para que os riscos possam ser geridos dentro de uma "margem de segurança” à saúde (CAPONI, 1997). No contexto estudado, constataram-se condições precarizadas para a gestão dos "riscos" ligados ao trabalho relacional de cuidado. De acordo com o relato das auxiliares, as más condiçôes de trabalho (como, por exemplo, jelcos de má qualidade) fazem com que elas se sintam "maltratando" as crianças e fiquem "mal emocionalmente", sintam em si a dor das crianças, fiquem "cansadas", "estressadas", não fiquem com a "cabeça legal”. Assim, acabam tendo impedida a realização prazerosa e bem sucedida (com qualidade, produtividade e segurança para a saúde de quem trabalha) de sua atividade.

Emocionalmente, você fica mal com aquilo (...) uma coisa que você poderia ter dado um furo na criança, entendeu, quando você pega um jelco bom (...) você coloca..., ele introduz na boa..., agora, quer dizer... a gente fica ali maltratando, maltratando, maltratando e a sua cabeça também não fica legal, né.

A gente sabe que é ruim, mas tem que fazer. E isso cansa a gente, cansa, porque o material é de péssima qualidade! 'Ai, se fosse em mim, que dor!'. Você vai lá, você vai introduzir na criança e você vai sentir em você aquela dor que a criança ta sentindo.

\section{Considerações finais}

Os dados desta pesquisa, incluindo aqueles gerados durante os encontros de validação, certamente indicam que a análise das condições de trabalho deve 
considerar a dimensão relacional da atividade de cuidado. Tal aspecto nos parece particularmente importante ao se tratar do trabalho em uma Unidade Neonatal, especialmente por esta envolver a relação direta com bebês e seus familiares (predominantemente mães).

É com esse olhar que podemos entender a afirmação de que "desde o momento que a gente ta aqui, tá na chuva pra se molhar né, não dá pra gente deixar de atender". Afirmação que mostra a intensa mobilização afetiva presente nessa atividade e que nos levou a concluir que não atender às mães parece ser mais nocivo à saúde do que ter que cuidar de um número excessivo de bebês.

Deve-se atentar também para o fato de que a atividade de cuidado, nesse setor, requer observação contínua (dos bebês, principalmente, mas também das mães e suas relações com os bebês) e uma forte mobilização do corpo-si, impedindo inclusive que as trabalhadoras fiquem sentadas e que tenham pausas reais (isto é, que se "desliguem" do trabalho durante o horário de almoço). O desconforto gerado pelos ruídos e pelo uso de materiais de má qualidade torna-se um problema mais significativo em virtude de afetar o próprio desenvolvimento da atividade. São condiçóes materiais que produzem forte incômodo porque as obrigam a estabelecer uma relação indesejável com os usuários, como se fossem elas as responsáveis pela nocividade existente.

Percebemos o quanto é difícil fixar o número ideal de bebês a cargo de cada auxiliar - embora seja claro que, no quadro atual, há uma superlotação. Algumas se arriscam a dizer que cada auxiliar deveria cuidar de no máximo três bebês (e nunca de cinco, como costuma ser), salientando, porém, que essa equação também depende da gravidade e da complexidade do problema da criança. O estado de saúde desta é, portanto, um componente que gera uma variabilidade intrínseca a essa atividade, repercutindo nos níveis de mobilização do corpo-si.

Um paradoxo problemático se coloca por fim para reflexão: como poderia se dar a luta pela limitação do número de atendimentos por auxiliar de enfermagem - melhorando assim suas condições de trabalho - se elas entendem que têm o compromisso de cuidar de todos, apesar de tudo, como uma espécie de regra de ouro de seu ofício? 
BRITO, J. Trabalho prescrito. In: PEREIRA, I.B.; LIMA, J.C. (Org.). Dicionário da Educação Profissional. 2a ed. revista e ampliada. Rio de Janeiro: EPSJV, 2009. p.440-445.

BRITO, J. Trabalho real. In: PEREIRA, I.B.; LIMA, J.C. (Org.). Dicionário da Educação Profissional. 2a ed. revista e ampliada. Rio de Janeiro: EPSJV, 2009. p.453-459.

BRITO, J.; ATHAYDE, M. Trabalho, Educação e Saúde: O ponto de vista enigmático da atividade. Rev. Educação, Saúde e Trabalho, v. 1, n. 2, p. 63-89, 2003.

BRITO, J.; ATHAYDE, M.; NEVES, M.Y. Programa de Formação em Saúde, Gênero e Trabalho nas Escolas: Cadernos de Método e Procedimentos. João Pessoa: EdUFPb, 2003. 92 p. CANGUILHEM, G. O normal e o patológico. Rio de Janeiro: Forense Universitária, 2002.307p. CAPONI, S. Georges Canguilhem y el estatuto epistemológico del concepto de salud. História, Ciência, Saúde, Rio de Janeiro, v.4, n. 2, p. 287-307, 1997.

CLOT, Y. A função psicológica do trabalho. Petrópolis: Vozes, 2006. 222p.

CRU, D. Les règles du métier. In: DEJOURS, C. (Org.) Plaisir et souffrance dans le travail. Paris: AOCIP; 1987. p. 29-42.

DEJOURS, C. Addendum. Da psicopatologia à psicodinâmica do trabalho. In: LANCMAN, S.; SNELWAR, L. (Org.). Christophe Dejours: Da psicopatologia à psicodinâmica do trabalho. Rio de Janeiro: Fiocruz, 2004. p. 47-104.

. Subjetividade, trabalho e ação. Rev Produção, v. 14, n. 3, p. 27-34. Set/Dez 2004.

. Por um novo conceito de saúde. Revista Brasileira de Saúde Ocupacional, v. 14, n. 54, abr.-jun., p. 7-11. 1986.

DURRIVE, L. Caixa de ferramentas - O fio condutor do animador. In: ENCONTRO FRANCO-BRASILEIRO DE ANÁLISE PLURIDISCIPLINAR DO TRABALHO, 1. 2001, Niterói/ Rio de Janeiro. Anais... Niterói/ Rio de Janeiro: NEICT/ CT/ Universidade Federal Fluminense, p. 67-86. 2001.

ESTRYN-BEHAR, M. et al. Santé, satisfaction au travail et abandon du métier de soignant. Etude PRESST-NEXT Partie 1. Disponível em: < www.presst-next.com >. Acesso em: 02 jan. 2006.

FAÏTA, D. Análise dialógica da atividade profissional. Rio de Janeiro: Imprinta Express, 2005.150p.

FRANÇA, M.B. Uma comunidade dialógica de pesquisa: atividade e discurso em guichê hospitalar. São Paulo: Fapesp, 2007. 327p.

GAÍVA, M.A.M.; SCOCHI, C.G.S. Processo de trabalho em saúde e enfermagem em UTI neonatal. Rev. Latino-americana de Enfermagem, Ribeirão Preto, v. 12, n. 3, p. 469-476, 2004. 
GUERIN, F. et al. Compreender o trabalho para transformá-lo. A Prática da Ergonomia. São Paulo: Edgard Blücher, 2001. 200p.

LAMY FILHO, F. A equipe da UTI neonatal. In: MOREIRA, M.; BRAGA, N.; MORSCH, D. (Org.). Quando a vida começa diferente: o bebê e sua família na UTI neonatal. Rio de Janeiro: Fiocruz, 2003. p. 107-116.

LAZARUS, R.S.; FOLKMAN, S. Stress appraisal and coping. New York: Springs, 1994. 456p. LOPES, M.J.M.; LEAL, S.M.C. A feminização persistente na qualificação profissional da enfermagem brasileira. Cadernos Pagu n. 24, p.105-125, 2005.

MOREIRA, M. C. N., Imagens no espelho de Vênus: mulher, enfermagem e modernidade. Rev. Latino-americana de Enfermagem, v. 7, n. 1, p. 55-65, 1999.

ODDONE, I. et al. Redécouvrir l'expérience ouvrière. Paris: Sociales, 1981. 260 p.

OSORIO-DA-SILVA, C. Curar Adoecendo: um estudo em busca da saúde, da inventividade e da vida. 1994, 137 p. Dissertação (Mestrado em Saúde Pública) - Escola Nacional de Saúde Pública, Fundação Oswaldo Cruz, Rio de Janeiro, 1994.

Vida de hospital: a produção de uma metodologia para o desenvolvimento da saúde do profissional de saúde. 2002, 128 p. Tese (Doutorado em Saúde Pública) - Escola Nacional de Saúde Pública, Fundação Oswaldo Cruz, Rio de Janeiro, 2002.

REGO, M.P.C.Trabalho Hospitalar e Saúde Mental: o caso de um hospital geral e público no município do Rio de Janeiro. 1993, 126 p. Dissertação (Mestrado em Saúde Coletiva) - Instituto de Medicina Social, Universidade do Estado do Rio de Janeiro, Rio de Janeiro, 1993.

SCOCHI, C.G.S. et al. A organização do trabalho na assistência ao recém-nascido em berçários da regional de Ribeirão Preto - SP. Brasil - 1992. Rev. Latino-americana de Enfermagem, Ribeirão Preto, v. 5, n.1, p. 27-36, 1997.

SCHWARTZ, Y. A comunidade científica ampliada e o regime de produção de saberes. Trabalho \& Educação, Belo Horizonte, n.7, p.38-46, 2000.

. Trabalho e uso de si. In: SCHWARTZ, Y.; DURRIVE, L. (Org.). Trabalho e Ergologia: conversas sobre a atividade humana. Niterói: Eduff, 2007. p.191-206.

SCHWARTZ, Y.; DURRIVE, L. (Orgs.). Trabalho e Ergologia: conversas sobre a atividade humana. Niterói: Eduff, 2007. 308p.

SEIFERT, A.M.; MESSING, K. Écouter et voir dans un monde technique: Effets de la discontinuité des horaires sur l'activité de travail des infirmières. Pistes [online], vol. 6, no. 1, 2004. Disponível em: <http://www.pistes.uqam.ca/v6n1/pdf/v6n1a3.pdf >. Acesso em: 03 jun. 2010.

ZARIFIAN, P. Objetivo Competência: por uma nova lógica. São Paulo: Atlas, 2001. 200 p. ZARIFIAN, P. Mutação dos sistemas produtivos e competências profissionais: a produção industrial de serviço. In: SALERNO M. (Org.). Relação serviço: produção e avaliação. São Paulo: SENAC; 2001. p. 67-93. 
${ }^{1}$ Cerca de $90 \%$ de seu quantitativo e, para destacar essa questão de gênero, a partir desse ponto, vamos denominá-las no feminino.

${ }^{2}$ Esta pesquisa resultou na dissertação de mestrado $A$ dimensão relacional do trabalho de auxiliares de enfermagem de uma unidade neonatal: uma análise do ponto de vista da atividade, de Letícia Pessoa Masson, e contou com a contribuição de Pérola Grimberg e Aline Candida da Cunha, estagiárias de iniciação científica (PIBIC/CNPq), e da doutoranda Luciana Gomes (bolsista CNPq). Foi apoiada pela CAPES (bolsa de mestrado), CNPq (bolsa de iniciação científica) e pela FAPERJ (financiamento de sua $2^{\text {a }}$ fase).

${ }^{3}$ Utilizamos esta expressão ao longo de todo o artigo como referência ao conjunto de serviços de Neonatologia oferecidos pelo hospital-maternidade em questão.

${ }^{4} \mathrm{O}$ grupo de plantão que apresentou o maior número de auxiliares que demonstraram interesse (através da inscrição voluntária, a partir da divulgação em todos os plantôes) em participar dos encontros.

${ }^{5}$ Tais encontros ocorreram ao longo do mês de dezembro de 2007. 


\section{The relational dimension of the care activity and the working conditions in a neonatal unit} This paper focuses on the working conditions of nursing technicians of Neonatal Units, considering the relational dimension of the care activity. Having as main epistemological references Canguilhem's concept of health of and the Ergological perspective, the research was based on the clinical approaches of work, including the following methods: direct (observations) and indirect (talks and meetings about work with the technicians); analysis of documents on the previous norms concerning this work. The analysis dealt basically with the groups' language production. Some results can be highlighted: the development of this care activity implies intense mobilization of workers; the possibility of not assisting the mothers who arrive to have their babies seems to be more noxious to these technicians than to work with an overload of patients; the precarious conditions of work are producers of pathogenic suffering, once the pleasant and well-succeeded realization of this activity is hindered.

> Key words: Neonatal Unit; nursing technicians; working conditions; care activity; maternity hospital. 